\title{
DOS ENGENHOS AOS SOBRADOS: MEMÓRIAS E FICÇÕES EM GILBERTO FREYRE E JAYME GRIZ
}

\author{
Luciane Alves Santos* \\ Maria Alice Ribeiro Gabriel**
}

\begin{abstract}
Resumo: O propósito deste artigo é analisar algumas histórias de fantasmas elaboradas pelos contemporâneos Gilberto Freyre e Jayme Griz na forma de relatos ou memórias que abordam o sobrenatural. Jayme Griz compilou testemunhos orais de antigos escravos, descendentes de escravos, trabalhadores das plantações de cana-de-açúcar e das usinas canavieiras. Gilberto Freyre organizou relatos de fonte oral e documental quando dirigiu o velho jornal A Província em 1929. Em seu trabalho, transcreveu e pesquisou histórias de aparições e casas mal-assombradas, casos provenientes dos arquivos familiares, históricos e policiais da cidade do Recife. Em comum, ambos descrevem, por diferentes pontos de vista, as memórias de um mundo em transição entre os séculos XIX e XX.
\end{abstract}

Palavras-chave: Gilberto Freyre. Jayme Griz. História. Literatura. Memória.

Este artigo resulta de uma comunicação sobre Assombrações do Recife Velho (1951), de Gilberto Freyre, e O Cara de Fogo (1969), de Jayme de Barros Griz, realizada durante o VII Simpósio de História Cultural: Escritas, Circulação, Leituras e Recepções, ocorrido entre 10 e 14 de novembro de 2014, na Universidade de São Paulo. Discute-se, sucintamente, a presença do sobrenatural nos relatos contextualizados na passagem do Brasil colonial ao republicano e os aspectos que atualizam a memória histórica local nessas narrativas.

Apesar de pouco divulgado, o conjunto da obra de Jayme Griz é significativo, formado pelo rico acervo das canções, lendas, mitos e tradições de Pernambuco. São narrativas em tom de rapsódia, sobre o decadente Nordeste escravagista e patriarcal de fins do século XIX e início do século XX, que lhe conferem o valor de pesquisador da tradição popular.

As histórias de $O$ Cara de Fogo retratam a extinção dos antigos banguês da zona da mata pernambucana e implantação das usinas canavieiras; já os relatos de Assombrações do Recife Velho, segundo Freyre definiu no prefácio à primeira edição da obra, formam um "ensaio" cujas "páginas que se seguem não são de Sociologia alguma do sobrenatural" (FREYRE, 2000, p. 28) e provêm de "velhos e honestos moradores da cidade (...) conhecedores de muita intimidade do velho Recife: inclusive casos de assombração" (FREYRE, 2000, p. 28).

\footnotetext{
* Doutora em Letras pela Universidade de São Paulo. Professora Adjunta do Departamento de Letras (campus IV) da Universidade Federal da Paraíba. Líder do grupo de pesquisas Variações do Insólito: do mito clássico à modernidade. UFPB/CNPq. E-mail: luciane45@gmail.com.

** Doutora em História Social pela Universidade de São Paulo. Pesquisadora vinculada ao grupo Variações do Insólito: do mito clássico à modernidade. UFPB/CNPq. E-mail: rgabriel1935@gmail.com.
} 
Ao lado da função de transmissão da memória social, que evolui em confrontação com o mundo moderno, é possível detectar elementos da história e da tradição dos antigos engenhos nas duas obras, ambientadas em uma época de transformações na distribuição do tempo, ritmo e organização do trabalho. Ao transcrever os relatos dos contadores de histórias locais, Freyre e Griz assumem outras funções, além de compiladores, entrevistadores e ouvintes, são mediadores no diálogo entre cultura oral e patrimônio escrito de um mundo que se extingue, o das "zonas do açúcar, por excelência, e muito ligadas aos negros" (GRIZ, 1969) e o dos "mistérios que se prendem à cidade do Recife" (FREYRE, 2000, p. 35).

O protagonista de $O$ Cara de Fogo é o homem de "muitas atividades no engenho", "dos últimos banguês de ontem para as usinas de hoje" (GRIZ, 1969, p. 98). Exceto por lacônico senhor de engenho cioso de sua propriedade, as abusões são aparições quase mudas: o "zumbi do boi", "o cavalo fantasma", fantasmas da mata, "a alma do maquinista penando no fogo da caldeira" ou escravos assassinados. Os fantasmas de Assombrações do Recife Velho seguem o modelo dos espectros silenciosos de Griz, salvo o suposto espírito de Raul Pompéia que se comunicou por escrito em "um centro de sessões de espiritismo que chegaram a ser freqüentadas por alguns dos doutores mais ilustres da cidade" (FREYRE, 2000, p. 91).

Embora o testemunho dos espectros não prevaleça nessas obras, eles impõem sua presença à memória dos vivos, validando o estatuto de Pierre-François Gorse (2003, p. 151): "Le récit de fantôme s'instaure donc comme un espace matériel, espace de mots, espace labyrintique, qui favorise le surgissement d'une immaterialité, d'un fantasme" . Mesmo antes de deixar as formas do anonimato pelas literárias, a memória coletiva inscreve-se nesses relatos, através da herança cultural imediata, dos símbolos e ícones da tradição longínqua, ou da história cultural das representações imagéticas de eventos passados: epidemias, guerras, migrações, transformações culturais, urbanas, ecológicas, econômicas, espaciais e laborais.

Após breve comentário sobre Assombrações do Recife Velho e O Cara de Fogo, este artigo divide-se em três partes. A primeira refere-se ao papel da memória e sua relação com os relatos da tradição oral; a seguinte comenta a associação entre espaço e motivos míticos em seu significado histórico; e a última parte aborda o conceito de memorate, discute sua apropriação pela Literatura e vínculo com a legenda. Os estudos de Jacques Le Goff, Jan Vansina, John Robert Colombo e Lauri Honko fornecem o aporte teórico desta análise.

\section{ASSOMBRAÇÕES DO RECIFE VELHO (1951)}

A coletânea Assombrações do Recife Velho foi idealizada quando Freyre dirigia o jornal A Província. No prefácio à $1^{\mathrm{a}}$ edição, o autor (2000, p. 31) descreve-se como "organizador deste livro de histórias que não deixam de ser história: história de uma cidade tão célebre pelas assombrações como pelas revoluções”. Mas é no breve prefácio à $2^{\mathrm{a}}$ edição, de 1970, que Freyre esclarece o propósito geral da obra:

\footnotetext{
1 “A narrativa de fantasmas se instaura portanto como um espaço material, espaço das (palavras), espaço labiríntico, que favorece o surgimento da imaterialidade, de um fantasma.” Tradução nossa.
} 
Este livro não pretende ser contribuição senão muito modesta para o estudo de um aspecto meio esquecido do passado recifense: aquele em que esse passado se apresenta tocado pelo sobrenatural. Pelo sobrenatural mais folclórico que erudito, sem exclusão, entretanto, do erudito. Mas sem que tenha sido preocupação do Autor entrar no mérito, por assim dizer, de qualquer desses sobrenaturais, cuja presença, real ou suposta, apenas constata, através de testemunhos, de experiências, de aventuras das chamadas psíquicas que teriam sido vividas por uns tantos recifenses em ambientes e em circunstâncias próprias do Recife: os de sua condição de cidade não só situada à beira-mar como cortada por dois rios; de burgo por algum tempo judaico-holandês e não apenas íbero-católico; de capital de província e de Estado depois de ter sido simples povoação de pescadores; de sede de vários conventos; de centro de atividades culturais importantes; de grande mercado de escravos trazidos da África; de espaço urbano caracterizado por sobrados de tipo esguio, de feitio mais nórdico do que ibérico: provável influência holandesa ou norte-européia sobre sua arquitetura. Vários desses sobrados ganharam fama de mal-assombrados (FREYRE, 2000, p. 21).

As histórias que integram essa coletânea de relatos foram "Quase todas recolhidas diretamente de boas fontes orais. De velhos e honestos moradores da cidade", recorda Freyre (2000, p. 30), ou de amigos, como Evaldo Cabral de Melo, que recolheu de gente antiga informações sobre assombrações célebres. "E quatro ou cinco casos foram recolhidos em páginas de cronistas coloniais ou do tempo do Império e não da tradição oral ou popular. Nem dos arquivos policiais" (FREYRE, 2000, p. 30-1). Se Assombrações do Recife Velho retrata "os mistérios da vida e da morte" de um Recife mais moderno, "de espaço urbano caracterizado por sobrados de tipo esguio", O Cara de Fogo reconstitui, pela tradição oral, a rotina dos burgos de açúcar: "No passado, ali floresceu uma aristocracia de senhores rurais. Senhores de engenho. Senhores de terras e de vastos coqueirais" (GRIZ, 1969, p. 158).

Transcrever fatos sobrenaturais, fora do domínio da ficção, já fora algo pretendido antes por Daniel Defoe, cujo Essay on the History and Reality of Apparitions (1727) teve seus relatos individuais sobre fantasmas incorporados a coleções a respeito do sobrenatural publicadas no século XIX. Andrew Lang coletou histórias de fantasmas e reuniu-as em The Book of Dreams and Ghosts (1897), assim como Nicolas Camille Flammarion o fez em Les Maisons Hantées (1924). Defoe e Freyre escreveram sobre o tema na forma de "ensaio", mas o escritor inglês publicou igualmente contos e histórias divertidas de fantasmas no plano da ficção, escolhido por Griz para descrever as assombrações dos engenhos pernambucanos.

\section{O CARA DE FOGO (1969)}

"Jayme Griz representa no Nordeste os ecos da velha tradição oral; das antigas estórias contadas aos meninos nos terraços das Casas Grandes de engenho e fazenda em toda a extensa área nordestina", afirmou Pessoa de Morais em prefácio a $O$ Cara de Fogo (GRIZ, 1969, p. 9). Griz reuniu notável acervo folclórico sobre o contexto cultural da zona da mata pernambucana: cantigas, crendices, estórias locais, lendas, misteres e provérbios. "Todos os contos do livro procuram trazer essa outra visão do Nordeste: a visão mística pejada do fantástico, fugindo do puro realismo convencional" (GRIZ, 1969, p. 13). No plano histórico, "Aratinga", "Barbalho", "Gigante", "Gravatá", "Liberdade" e "Mata-Virgem" são antigos engenhos citados, reduzidos a um "Mundo de sombras e fantasmas" (GRIZ, 1969, p. 26). 
Pereira da Costa (1898) fez um levantamento da crise do açúcar em Pernambuco em 1886, agravada pela Abolição, que levou à bancarrota muitos senhores de engenho. Revigorados pelo incentivo de um subsídio do governo imperial, os bancos do Brasil e de Crédito Real rapidamente expandiram suas operações levantando financiamentos para usinas emergentes (EISENBERG, 1974, p. 80). Em "O Fantasma Negro do Bueiro da Usina Cucaú", o narrador, neto de escravos, alude à transição do engenho ao sistema mecanizado das usinas:

\begin{abstract}
Em Pernambuco usina sempre nasceu nas terras dos engenhos. Tudo quanto foi engenho de ontem está hoje na barriga das usinas. [...] $\mathrm{O}$ engenho de que falei quando vosmecê esteve aqui, há três dias atrás, e que ficava onde está hoje plantada a usina Cucaú, é possível tivesse ele o nome da usina de hoje, pois acontecia sempre a usina, tomar o nome do engenho que ela engulia, como diz o povo (GRIZ, 1969, p. 93-94).
\end{abstract}

$\mathrm{O}$ elemento folclórico regional é explorado na transposição de mitos e assombrações do Recife "fora-de-portas": paixões trágicas, como em "Cícero Grande", "Meu cavalo deu um tope" e "O Cavalo Fantasma da Estrada do Engenho Barbalho"; visagens de animais encantados, como "o zumbi do boi", o cão "que também era um fantasma", "O Cavalo Fantasma da Estrada do Engenho Barbalho" e "Os Caititus das Matas do Engenho Gigante".

Sofrimentos da escravidão são narrados em "Meu cavalo deu um tope", "A Enforcada da Mata do Chareta" e "Assombração no Rio Formoso", ambientados nas casas-grandes e sobrados com notícia de "botija enterrada com dinheiro e ouro do falecido senhor de engenho" (GRIZ, 1969, p. 100), além do próprio senhor "orgulhoso e duro [...] Desses que em tempo ruim morrem mas não se entregam" (GRIZ, 1969, p. 167-8). Em síntese, a obra narra a história "que fala dos bangüês de ontem e das usinas de hoje" (GRIZ, 1969, p. 98).

Alguns dos mitos descritos por Griz são redefinidos por "influências contraditórias - européias, africanas, indígenas" (FREYRE, 2000, p. 55) ou transpostos para "a história sobrenatural do Recife" de "dentro-de-portas", relatada por Freyre, o que permite analogias recíprocas entre as duas obras, nas quais memória e tradição popular confluem, mitologizando elementos da realidade. Configurados em narrativas, esses elementos reforçam estruturas da memória social e garantem a continuidade cultural da história de lugares e comunidades.

FONTES E REGISTROS DA CULTURA ORAL NA TRADIÇÃO POPULAR E MEMÓRIA COLETIVA

A distinção do presente e do passado nas sociedades, segundo Jacques Le Goff (2006, p. 205-6) relaciona-se "a essa escalada na memória e essa libertação do presente que pressupõem a educação e, para além disso, a instituição de uma memória coletiva, a par da memória individual". Em prefácio ao estudo de Paul Cohen (2009, p. xv), Speaking to History, John R. Gillis notou que a Historiografia contemporânea tenta preencher a lacuna entre suas abordagens do passado e a consciência inscrita na memória 
popular. Pierre Nora, Michael Kammen e David Lowenthal já haviam ponderado antes sobre transpor os "fossos" que separam folclore, literatura, mitologia e história, questionando as fronteiras disciplinares que reforçam a segregação entre esses campos, questão envolvendo o tema da memória.

Analisar a presença das memórias, coletivas e individuais, nos casos citados por Freyre e ficcionalizados por Griz pressupõe considerar que certos aspectos do estudo da memória, "podem evocar, de forma metafórica ou de forma concreta, traços e problemas da memória histórica e da memória social" (MORIN; PALMARINI, 1974 apud LE GOFF, 1996, p. 423). O repertório de relatos da oralidade é pertença comum de um grupo, nem sempre validada pelo estatuto literário das narrativas escritas (DICKERSON, 1996, p. 111).

Certamente Griz reuniu casos de moradores locais e descendentes de escravos que, fora do domínio patriarcal de seu senhor, migraram para as cidades. Com a decadência dos antigos senhores, engenhos considerados "de fogo-morto" transformaram-se em ruínas e os ainda produtivos passaram a ser propriedade de usinas modernas (EISENBERG, 1974, p. 85).

As fontes documentais utilizadas por Freyre em Assombrações do Recife Velho foram: a entrevista, o testemunho direto e os arquivos da polícia, registros oficiais. Em 1929, "quando foi uma noite procurado por sisudo morador de sobrado de São José", o diretor d'A Província encarregou o "repórter policial do jornal, que era o Oscar Melo, de vasculhar nos arquivos e nas tradições policiais da cidade o que houvesse de mais interessante sobre o assunto: casas mal-assombradas e casos de assombração" (FREYRE, 2000, p. 29). Nos registros materiais fornecidos pelo "chefe de polícia de então - Eurico de Sousa Leão", Freyre verificou: "Queixas contra espíritos desordeiros. Denúncias contra ruídos de almas penadas. Pedidos à polícia para resolver questões violentamente psíquicas" (FREYRE, 2000, p. 29).

A miscelânea desses relatos é consistente com as tradições pernambucanas, "as relações míticas e místicas entre o Recife e o Nordeste” (FREYRE, 2000, p. 39). Histórias de pessoas morrendo traumaticamente e se tornando fantasmas e legendas sempre se mantiveram em circulação na cultura oral - caso de José Gomes, o "Cabeleira", criminoso que aterrorizou o Recife no século XVIII e cuja história foi contada pelo romancista Franklin Távora, em 1876:

"Entretanto, morto Cabeleira para o recifense civilizado, tanto quanto para o matuto esclarecido do interior, ele passou, para muita outra gente, a mais que existir: a subsistir à própria morte. A existir como mito. E esse mito, um mito de terror" (FREYRE, 2000, p. 60).

O retorno de um fantasma é um dos motivos mais recorrentes na cultura popular. Há motivos tradicionais universais, por exemplo, o retorno de um morto para revelar um tesouro escondido: "E para o povo mais simples, tanto flamengos como jesuítas e judeus deixaram tesouros enterrados no Recife: tesouros ligados a assombrações" (FREYRE, 2000 , p. 55). Não se pretende aqui uma relação exaustiva de motivos comuns às obras de Freyre e Griz, e sim notar a continuidade da tradição operando nas legendas e memorates $^{2}$ citados.

\footnotetext{
${ }^{2} \mathrm{O}$ estudo de Linda Dégh e Andrew Vázsonyi (1974, p. 225), partindo da definição precursora de Carl Wilhelm Von Sydow, discute a distinção do memorate de outras formas narrativas, tais como a legenda, a
} 
Legados da memória, os relatos da tradição oral incorporam todo tipo de valores, tornando-se verdadeiros imperativos morais, do mesmo modo que emoções e símbolos atuam como estabilizadores da memória e, por conseguinte, da identidade coletiva. Muitas concepções recentes sobre a memória, privilegiando aspectos de estruturação biológicos e psicológicos, são herdeiras de estudos conduzidos entre o final do século XIX e a primeira metade do século XX. Assim, alguns cientistas foram "levados a aproximar a memória de fenômenos diretamente ligados à esfera das ciências humanas e sociais" (LE GOFF, 1996, p. 424). Pierre Janet, por exemplo, considerou o "comportamento narrativo" o ato mnemônico fundamental, caracterizado "antes de mais nada pela sua função social, pois que é comunicação a outrem de uma informação, na ausência do acontecimento ou do objeto que constitui o seu motivo" (FLORÈS, 1972, p. 12 apud LE GOFF, 1996, p. 424-425, grifo do autor). Já o filósofo Henri Atlan analisou a conexão existente entre linguagem e memória do ponto de vista biológico e social, ressaltando a função estruturadora do pensamento:

\begin{abstract}
A utilização de uma linguagem falada, depois escrita, é de fato uma extensão fundamental das possibilidades de armazenamento da nossa memória que, graças a isso, pode sair dos limites físicos do nosso corpo para estar interposta quer nos outros quer nas bibliotecas. Isto significa que, antes de ser falada ou escrita, existe uma certa linguagem sob a forma de armazenamento de informações na nossa memória (ATLAN, 1972, p. 461 apud LE GOFF, 1996, p. 425).
\end{abstract}

O contraste entre oralidade e escrita é discutido em Le fantastique entre l'oral et l'écrit (1980), análise crítica da distinção entre fantástico literário e folclórico. Para Jean Molino, o fantástico oral foi influenciado pelo fantástico escrito, mas, em sentido inverso, a literatura fantástica apenas adquire verdadeira significação em relação às fontes e formas orais de que é prolongamento. Do ponto de vista antropológico, existe uma evidente correspondência entre o fantástico literário e o da tradição oral (MOLINO, 1980, p. 32).

O estudo da memória social constitui um dos principais meios na abordagem dos problemas do tempo e da história. Analisar a memória histórica exigiria ao pesquisador conceder "importância especial às diferenças entre sociedades de memória essencialmente oral e sociedades de memória essencialmente escrita como também às fases de transição da oralidade à escrita" (LE GOFF, 1996, p. 426). Para o propósito dessa investigação, convém estabelecer que nem sempre oralidade e literariedade são categorias mutuamente excludentes. Exemplo prolífico dessa conexão são as histórias de lugares assombrados ou "encantados".

\title{
O ESPAÇO DO MITO
}

Segundo Jan Vansina (1985, p. 125), cada cultura tem suas próprias representações do universo, envolvendo conotações espaciais. Como o tempo, o espaço é uma noção relativa, um lugar é considerado em relação a outros lugares. Os espaços mais importantes

legenda da memória (fict), o relato legenda (sagenbericht), a experiência reportada (Erlebnisbericht), o pseudo e quase-memorate ou legenda-memorats (sagenmemorate) e a nota da crônica (Chroniknotiz). 
vinculam-se ao lugar da criação de mitos. A visão que alguém tem de um espaço influencia sua visão histórica dos fatos. No passado, cristãos devotos visualizavam o Jardim do Éden na Mesopotâmia. No século XIII, os mapas europeus do mundo tinham a forma de disco, com Jerusalém ao centro. Assim a "Redenção" foi traduzida no espaço. Portanto, afirma Le Goff:

\begin{abstract}
Da mesma forma, como em geral um mito está ligado a um lugar ou a um espaço, a maneira como a Idade Média ocidental fixa seus heróis e maravilhas a lugares, mesmo que não sejam aqueles onde eles surgiram, concede-lhes um ponto de implantação geográfica significativo - seja geografia real ou imaginária (LE GOFF, 2009, p. 23).
\end{abstract}

Em Assombrações do Recife Velho, memórias associam-se a espaços reais, como a campina da Casa-Forte no Recife, onde "o próprio diabo dos brancos com toda a sua vermelhidão e toda a sua inhaca terrível de enxofre e de breu" apareceu a duas mulheres, conforme relatado a Freyre por "Josefina Minha-Fé, moradora dos arredores da CasaForte, salientando: 'Mas isso foi no tempo antigo'. Talvez ainda no século XVII: 'no tempo dos Framengo"” (FREYRE, 2000, p. 35). "Como mal-assombradas ficaram terras entre Casa-Forte e o Arraial: todo um sítio onde é tradição ter aparecido durante anos a figura de um guerreiro ruivo [...] que caíra morto na batalha de Casa-Forte (1645)" (FREYRE, 2000, p. 35).

O Recife é pródigo em lugares assombrados e "ermos sinistros": o Chora-Menino, "que por tanto tempo foi um descampado da cidade" (FREYRE, 2000, p. 37); "Outro lugar público com fama de mal-assombrado foi por muito tempo, e é um pouco ainda hoje, a Cruz do Patrão, no istmo que liga Recife a Olinda" (FREYRE, 2000, p. 37); o sítio do Encanta-Moça, a Avenida Malaquias, o Sítio da Capela, as “águas da Prata ou do Prata, em Apicucos" (FREYRE, 2000, p. 50); "E em águas do Capibaribe defronte do Sítio da Capela é tradição ter aparecido a um negro aflito não Iemanjá mas a Virgem Maria" (FREYRE, 2000, p. 47). Para Jan Vansina (1985, p. 18) o mito pode preservar informações extremamente antigas sobre o lugar. Assim, os lamentos noturnos no descampado do Chora-Menino concernem à memória comum da Setembrada pernambucana de 1831, não a uma reminiscência individual:

\footnotetext{
Não nos deixemos porém arrastar pela tentação de reduzir a história natural a história do Recife. Pois nesse ponto a tradição é de que naquele descampado houve matança e sepultamento de recifenses, inclusive de meninos e inocentes, numa das agitações que ensanguentaram o velho burgo. Pelo que durante anos o largo inteiro teria ficado malassombrado com o choro dos inocentes (FREYRE, 2000, p. 37).
}

A mente humana é capaz de comunicar, através de simbolismo estruturado, mensagens ocultas, as quais são verdades dolorosamente aniquiladoras para a condição humana, literalmente matérias de vida e morte, natureza e cultura (VANSINA, 1985, p. 162). A natureza da mensagem simbólica de certos relatos expressa a tentativa de assimilação de traumas coletivos, figurados na expressão do mito e do sobrenatural registrado pela tradição. 
A literatura do século XIX acentuou o interesse por histórias de fantasmas como um aspecto pitoresco do passado, mais interessante que o presente (HANDLEY, 2007). Lendas e Narrativas (1851), histórias populares da Península Ibérica medieval, foram publicadas por Alexandre Herculano nas revistas portuguesas $O$ Panorama e $A$ Ilustração, entre 1839 e 1844 . Assombrações do Recife Velho teve origem similar, quando A Província lançou "uma série de artigos a respeito do assunto" - casas mal-assombradas e casos de assombração - "artigos que fizeram algum ruído, embora apenas provinciano" (FREYRE, 2000, p. 29).

Existe uma relação de temas e motivos da tradição oral partilhada pelas duas obras. O histórico e o legendário perfazem a crônica literária do velho Portugal de Herculano. São histórias sobre as invasões mouriscas ("A destruição de Áurja”), maldições ("O Bispo Negro" e "O Emprazado”), o diabo (“A Dama Pé de Cabra”) e a Inquisição (“O Cronista"). Também Assombrações do Recife Velho apresenta histórias com maldições e visões premonitórias ("O velho Suassuna pedindo missa?" e "O vulto do salão nobre"), o diabo ("Um barão perseguido pelo diabo" e "A velha branca e o bode vermelho"), a Inquisição e "uma israelita de fortuna, Branca Dias", que "deitou a muita prata que tinha em casa em águas de Apicucos, desde então, segundo entendidos no assunto, malassombradas" (FREYRE, 2000, p. 36).

"Os mistérios que se prendem à história do Recife são muitos: sem eles o passado recifense tomaria o frio aspecto de uma história natural" (FREYRE, 2000, p. 35). Em vez da ameaça mourisca, dos "sarracenos de Mafamede", citados por Herculano, surgem aparições do domínio holandês, do "Recife ainda quente da presença de herege ruivo e vermelho nas suas ruas e nas suas casas" (FREYRE, 2000, p. 35). "E outro cronista do Recife, o Franklin Távora d'O Cabeleira" relata "em página ainda quente da tradição por ele recolhida da boca dos antigos" que uma noite, junto à Cruz do Patrão, "Apareceu o diabo africano naquela Salamanca recifense de negros" (FREYRE, 2000, p. 39-40).

"A grandeza das casas-grandes nas terras de plantio e dos sobrados do Rio Formoso, com o tempo se acabou" (GRIZ, 1969, p. 167). O sobrado, construção típica do burgo arcaico ou "fora-de-portas", é o cenário da maior parte das aparições, "no Recife dos primeiros anos do século XIX. O Recife colonial do tempo do governador português Luís do Rego" (FREYRE, 2000, p. 137). O engenho, pelas suas funções de residência senhorial, aproximava-se do castelo ou fortificação, enquanto o palacete, típico do Brasil republicano, pertencia às cidades em desenvolvimento, filhas da Revolução industrial. Conforme os distinguiu Le Goff:

\footnotetext{
Desde a Idade Média, ele (o castelo) era às vezes confundido com o palácio, mas é preciso distingui-los com cuidado na história da realidade e do mito. O palácio apresenta duas características específicas que o diferenciam do castelo medieval. Primeiro, trata-se essencialmente de uma residência real, ou pelo menos principesca, ao passo que o castelo medieval pertence a um simples senhor, embora os reis possam ter construído castelos medievais enquanto senhores. Além disso, das duas funções essenciais do castelo, a militar e a residencial, é esta última que o palácio privilegia, ao passo que o castelo medieval caracteriza-se pela primeira (LE GOFF, 2009, p. 74).
} 
Da mesma forma que o mito encerra a tentativa de assimilação de um evento traumático na memória coletiva, o espaço a que ele se atém pode associar-se aos valores da comunidade, por exemplo, a direita representando o superior e a esquerda, o inferior (VANSINA, 1985, p. 127). Segundo Le Goff, existe no espaço uma simbologia de prestígio. Na Antiguidade, a orientação fundamental do espaço valorizado era definida entre a direita e a esquerda. "A valorização era ir para a direita. Na Idade Média, o eixo de orientação valorizado vai do baixo ao alto. [...] As famílias ricas, sobretudo nas cidades onde a nobreza se instalou, procuram ter uma torre mais alta do que aquela de uma família rival” (LE GOFF, 1998, p. 129). As primeiras vilas desenvolveram-se numa extensão da vida nos engenhos. Em "Assombração do Rio Formoso" pode ser encontrada a seguinte definição desse processo:

\begin{abstract}
A cidade é situada à margem do Rio formoso, que lhe deu o nome. No passado, ali floresceu uma aristocracia de senhores rurais. Senhores de engenho. Senhores de terras e de vastos coqueirais. Senhores de outras tantas riquezas que as fecundas terras do velho município propiciaram. Ainda hoje a cidade tem evidentes sinais desse seu passado de riqueza e fartura. Velhas residências senhoriais, dizem bem ainda dos contatos desses antigos senhores de terra com o velho burgo (GRIZ, 1969, p. 158).
\end{abstract}

Nestor Goulart Reis descreve a arquitetura típica das primeiras moradias senhoriais, cujas grossas paredes em pedra correspondiam às instalações antigas. "Mas não devemos esquecer que os desenhos de Frans Post nos mostram em Pernambuco, mais de um século após a fundação de São Jorge, um número grande de edificações muito simples, feitas com terra e madeira" (REIS, 1999, p. 69). Essas construções modestas erigiam-se com técnicas mais fáceis de serem aplicadas com o aproveitamento da mão de obra indígena. O engenho do donatário apresentava a feição de quase fortaleza, uma ponta-de-lança em território indômito.

Informações sobre edificações em São Vicente, incluindo cartas de Tomé de Souza, mencionam significativo número de casas construídas em pedra. A correspondência do governador-geral informava que nessa época as casas estavam de tal modo espalhadas em São Vicente, que era impossível protegê-las com um muro, como fizera a outras povoações, ao Sul de Salvador, à exceção de Santos e São Vicente. Entretanto, ressalvava a segurança da maioria das construções de pedra locais. "Com muito maior razão, o donatário determinaria o uso do mesmo material, na construção do engenho de sua empresa" (REIS, 2005).

Provavelmente a arquitetura dos engenhos organizados à maneira de feudos isolados até primórdios do século XIX influiu no caráter autocrático de seus senhores, neles reinando soberanos, e, mais tarde, nas legendas que inspiraram, pois, segundo Vansina (1985, p. 107) um reino pode representar a expressão de todo um país, como o passado da casa real a de uma nação. Griz relata o caso do "orgulhoso e duro" ex-senhor de engenho do Rio Formoso: "Morreu assim o senhor velho com o seu ódio e a sua soberba, mas não abandonou a casa. [...] Quem não sabe da estória e nesse sobrado entra, sai de lá tangido pela visage de seu antigo senhor, que bota para fora quem lá entra para ficar" (GRIZ, 1969, p. 169). 
As visagens de $O$ Cara de Fogo relacionam-se à "terra de abusão" cuja memória está em vias de desaparecer: matas, estradas desertas, sítios e engenhos arruinados. Similarmente, os espaços ligados às visagens de Assombrações do Recife Velho são fragmentos da crônica do passado, expostos a partir de mentefatos.

\section{HISTÓRIAS DE FANTASMAS, MEMORATE, MENTEFATO E MITO}

Verificar a aproximação entre cultura oral e cultura escrita leva, inevitavelmente, ao conceito de mentefato, representação componente de crenças, valores ou ideias, a princípio, na mente dos partícipes de uma dada cultura. $\mathrm{Na}$ acepção de conceito classificatório, o termo mentefato sobrepõe-se à ideia de cultura encoberta - que diz respeito aos aspectos culturais não observáveis diretamente - e ao de cultura imaterial aspectos da cultura não expressos "solidamente" (que englobam variados artefatos). $\mathrm{O}$ termo pode designar fatos intelectuais relativos ao conhecimento, ao imaginário e também a experiências de ordem afetiva (GREEN, 1997, p. 555). Para Aaron Gurevith (1992, p. 195), as histórias de fantasmas caberiam ao domínio do mentefato, partilhando representações da memória coletiva de sociedades cujo pensamento permaneceu, em grande extensão, vinculado às categorias do mito.

John Robert Colombo (1996, p. 18) distinguiu as narrativas de fantasmas em conto (tale) e histórias de fantasmas (ghost story). Histórias de fantasmas seriam relatos de eventos ou experiências da ordem do sobrenatural ou paranormal in natura, encerrando, em certa medida, a ideação da testemunha, seguida do pensamento do próprio autor sobre o tema.

O relato sobre um espectro que assombra alguém, um local ou um objeto, é propriamente definido, para Colombo, como uma história de fantasmas. Esta pode dividir-se em duas categorias. A primeira é chamada conto e trata de assombração legendária ou tradicionalmente identificada. Em Assombrações do Recife Velho, o episódio da execução de frei Caneca, Joaquim da Silva Rabelo, em 1825, é certamente um conto, um relato tradicional:

\footnotetext{
É tradição recifense que os algozes escolhidos para executar frei Caneca - revolucionário de 24 e frade do Carmo - na forca armada no largo de Cinco Pontas, recusaram-se a cumprir a ordem do governo de Sua Majestade, porque viram todos no meio das nuvens, dentro de uma auréola, uma mulher de vestes branquíssimas e de beleza puríssima - igual à Nossa Senhora elogiada em latim nas ladainhas - a acenar-lhes que não tocassem no corpo do frade (FREYRE, 2000, p. 195).
}

O relato da tradição corresponde a uma necessidade humana profunda. Ele enriquece a vida presente encorajando a imaginação a (re)experienciar o passado e apresenta, invariavelmente, foco narrativo em terceira pessoa, como ocorre na Legenda áurea (1260).

O segundo tipo de história de fantasmas costuma ser narrado em primeira pessoa e expõe diretamente uma vivência individual. O interlocutor pode, nesse caso, questionar a credulidade, inteligência ou integridade do narrador e, acima de tudo, duvidar da 
interpretação que o informante emprestou ao evento ou experiência sobrenatural. É comum o narrador munir-se de estratégias de persuasão para "dizer somente a verdade, nada mais que a verdade". Não se requer do "ouvinte" ratificar aquele testemunho, e sim acreditar que o informante vivenciou uma experiência verídica para ele. Dificilmente essas histórias são relatos de "segunda mão" ou podem ser consideradas atinentes ao sobrenatural in natura, pertencem, antes, ao paranormal e são chamadas de "memorates" (COLOMBO, 1996, p. 18).

O termo memorate foi introduzido por Carl W. Von Sydow em 1934 e posteriormente redefinido com propósitos analíticos. Relato de "primeira-mão", o memorate fornece dados confiáveis ao pesquisador sobre aspectos efetivos de uma pesquisa experimental e revela em que situação a tradição foi atualizada, originando novos padrões de comportamento, além de informar sobre os contextos de crenças, suas formas de transmissão ou interpretação, e os modos e sistemas de preservação de tais crenças em sociedade (GREEN, 1997, p. 553). Para o folclorista, o memorate é o relato em primeira pessoa de experiência ou evento considerado verdadeiro. Não é referido como produto da imaginação ou obra de ficção, mas se apresenta na situação de verdadeiro depoimento para a audiência e o coletor (COLOMBO, 1996, p. 18).

No contexto das crenças folclóricas, segundo Lauri Honko (1964), investigadores orientados ao estudo sociológico de crenças primitivas e folcloristas pesquisando narrativas populares deparam com o mesmo material. Ambos poderiam beneficiar-se com a troca de ideias sobre seus métodos e resultados, o que nem sempre ocorre. $\mathrm{O}$ folclorista e o antropólogo reportam enfoques diversos sobre um mesmo memorate. Em outras palavras, a visão antropológica lida com seu corpus aceitando que diferentes peças de informação tenham o mesmo valor como evidência. Já o folclorista bem treinado seria mais cauteloso, ao notar que diferentes peças de informação representam variantes de diferentes gêneros da tradição.

No estudo do folclore, a análise dos gêneros tradicionais busca identificar conceitos e categorias para a crítica do material. O que seria, por exemplo, uma crença folclórica? Apesar de vaga, a expressão é bastante usada para definir itens da tradição. Por um critério formal de definição, a crença normalmente estipula seu tema com uma declaração direta e generalizada: "The barn spirit does not let you sleep in the barn; he drives you away" 3 é uma crença.

Pela generalização contida na declaração, alguém poderia questionar se essa é uma crença difundida. Na base de um amplo campo de evidências, a resposta seria afirmativa e a crença pertenceria à tradição coletiva. No caso de crença pouco conhecida no lugar, possivelmente ela pertencerá a uma tradição individual. Nesse caso, sua origem pode ser traçada, tendo o informante se apropriado de outros memorates ouvidos antes e quase sempre tal crença é fruto da criação de um coletor (HONKO, 1964, p. 9). E apesar da variedade de fontes nos contextos culturais, é possível divisar uma convergência de motivos ou elementos narrativos tradicionais no repertório dos memorates e relatos ficcionais de determinada época.

\footnotetext{
3 "O espírito do celeiro não deixa você dormir no celeiro; ele o expulsa". Tradução nossa. Nesse ponto, Honko (1964, p. 9) cita o relato da finlandesa Maria Savolainen, nascida em 1882, descrevendo seu encontro sobrenatural com um hobglobin, ou seja, um espírito guardião de celeiros.
} 
O motivo da casa abandonada teve forte apelo dramático durante o Romantismo, associado ao do encontro com o sobrenatural. Esses motivos foram assimilados inclusive pela poesia, notavelmente, por Emily Dickinson: "I leaned opon the Awe/ I lingered with Before". Na narrativa popular e na ficção, essa combinação pode ser vista no conto de mistério e de modo exemplar em "Assombramento" (1898), de Afonso Arinos de Melo Franco. O conto narra a história de um homem que decide pernoitar em uma casa de fazenda mal-assombrada:

\begin{abstract}
Por que seria que os tropeiros, ainda em risco de forçarem as marchas e aguarem a tropa, não pousavam aí? Eles bem sabiam que, à noite, teriam de despertar, quando as almas perdidas, em penitência, cantassem com voz fanhosa a encomendação. Mas o cuiabano Manuel Alves, arrieiro atrevido, não estava por essas abusões e quis tirar a cisma da casa mal-assombrada (ARINOS, 2006, p. 9).
\end{abstract}

Situação quase idêntica é narrada em “Assombração no Rio Formoso". Francisco ou Chico Cigano aceita pernoitar em um solar desabitado, "em busca de um pouso para aquela noite". Estranhos fenômenos mantêm-no acordado até ser expulso, de madrugada, pelo espectro do senhor de engenho que assombra o local: "Um dos costumeiros frequentadores da taverna, antigo morador da cidade, contou então o que sabia a respeito das assombrações do velho solar, de onde tinha sido Chico tangido por um fantasma" (GRIZ, 1969, p. 166-7). Pessoa de Morais definiu O Cara de Fogo como um desdobramento, "na forma literária do conto", das pesquisas do autor inclinado a ouvir histórias de fantasmas: "Seus contos, inclusive os do livro que se segue, resultam de acurado estudo anterior" (GRIZ, 1969, p. 13).

O caso d' "O sobrado da Rua de São José" citado por Freyre repete motivos dos relatos de Afonso Arinos e Griz, porém ambientado na cidade, e tendo por protagonista "ninguém menos que um repórter policial" que se muda para o "palácio enobrecido pelo tempo" "para retirar dali o dinheiro que dizem estar enterrado":

\footnotetext{
Na primeira noite balançaram-lhe a rede. Ouviu assovios. Baques. Móveis espatifando-se no chão. Repórter policial, pensou policialmente: deve ser gente. Pensando que estava com ladrões em casa, levantou-se, acendeu o candeeiro e correu todo o sobrado com a luz de querosene na mão (FREYRE, 2000, p. 162).
}

Na terceira noite "as cordas da rede partiram-se e o bravo foi jogado ao soalho". Ao amanhecer, deixou o sobrado: "E ficou acreditando em mal-assombrados" (FREYRE, 2000, p. 164). O estilo adotado na descrição das assombrações do Recife foi o do "escritor que tem na Sociologia (como outros na Medicina ou na Engenharia) seu mais constante ponto de apoio - embora seja principalmente escritor e não sociólogo" (FREYRE, 2000, p. 25). Iniciando pela história da Cruz do Patrão, A Província publicou uma série de artigos sobre casas mal-assombradas, que Freyre deliberou redigir sem a retórica característica de uma disciplina especializada: "E antes mesmo das primeiras notas serem trazidas pelo repórter para o diretor do jornal reduzi-las a histórias de sabor o mais possível popular" (FREYRE, 2000, p. 29). 
O folclorista, mitólogo e poeta finlandês Martti Haavio, em seu trabalho sobre os fantasmas ou espíritos domésticos (Suomalaiset kodinhaltiat, 1942) afirmou que os memorates revelam a ideação do narrador sobre sua experiência - que ele acredita ter acorrido realmente - conforme suas crenças. Para Honko (1964, p. 10), o memorate não é um tipo de legenda, mas forma sua própria categoria e seu conceito não possui conexão com a peculiar memorabile de André Joles. Entretanto, Ake Hultkrantz considerou a legenda um memorate transformado em tradição, partindo do princípio de que um encontro entre espíritos e seres humanos seja tomado por crença genuína (HULTKRANTZ, 1957 apud ROLPH, 1994, p. 82).

A relevância deste "encontro" foi declarada de modo análogo por Freyre (2000, p. 25): "Admitido, como alguns hoje admitem em Sociologia, que a conviç̧ão pode fazer sociologicamente as vezes da realidade, admite-se que possa haver associação por meios psíquicos, mesmo imaginários, de vivos com mortos”. Para Sasha Handley (2007, p. 33), ao focalizar a atitude da sociedade para com os mortos, as histórias de fantasmas, dramáticas representações da imortalidade, diluem a finalidade da morte por estender o processo ritual do luto e colmatar o abismo físico e conceitual que separa este mundo do outro.

\section{CONSIDERAÇÕES FINAIS}

Assombrações do Recife Velho e O Cara de Fogo complementam-se e dialogam entre si. Enquanto Jayme Griz revela as memórias e o ponto de vista dos que viveram, por muito tempo, à sombra patriarcal dos engenhos pernambucanos, Gilberto Freyre aborda a adaptação dessa população transferida das casas-grandes, fortalezas do tempo del-Rei e senzalas para sobrados e casas térreas adaptados à cidade, sem traço algum de residência senhorial.

Simultaneamente a essa época de fausto que expira, desaparece toda uma fauna e flora mítica. Escravos libertos aceitam o êxodo para as povoações vizinhas ou são integrados ao regime de trabalho das usinas. No entanto, as visagens desse mundo que se extingue persistem em assombrar os vivos, fornecendo um testemunho subjacente à memória dos homens. O Recife em que "o esplendor do gás hidrogênio" vinha "substituir a luz amortecida do azeite de Carrapato" é assombrado por fantasmas do domínio judaicoholandês, mortos de revoluções libertárias, almas de senhores de engenho e "não faltam casos sem explicação alguma. Choros que não se parecem com o guincho de animais e risadas, como a do chamado Boca-de-Ouro, que não têm semelhança alguma com as risadas dos vivos" (FREYRE, 2000, p. 19).

As ações de contar histórias e recordar correlacionam práticas similares: a ordenação de imagens e fatos por uma estrutura histórica ou psiquicamente significativa no plano coletivo ou individual. As ciências sociais contemporâneas, notadamente entre as décadas de trinta e setenta do século XX, privilegiaram o conceito de cultura e a análise conceitual. Após a Segunda Guerra, os cientistas sociais detiveram-se nos aspectos filosóficos da Antropologia. O requisito essencial de uma investigação comparativa era que os conceitos empregados em cada ciência fossem consistentes com outras classes de 
dados ou fatos empiricamente verificáveis. Do ponto de vista da Antropologia, da Sociologia e da pesquisa folclórica, a análise dos gêneros tradicionais de forma fixa (contos, lendas migratórias, baladas e provérbios) era um dos meios auxiliares no estudo da cultura popular. Nesse contexto surgiram Assombrações do Recife Velho e $O$ Cara de Fogo.

Interpretações enfatizando características antropológicas ou literárias dessas histórias de fantasmas ressaltam a vida e a dimensão social da tradição, estudando-as primordialmente do ponto de vista da situação narrativa, da técnica narrativa e da personalidade e repertório do narrador (HONKO, 1964, p. 8). Essa orientação vinculouse, atualmente, a estudos históricos sobre memória e mobilidade cultural. Sob a perspectiva social da memória coletiva, mito e legenda, além da função de exemplum, podem atuar conjurando os horrores vinculados a determinados espaços, fatos e eventos que devem ser preservados do esquecimento.

\section{REFERÊNCIAS}

COHEN, Paul. Speaking to History. Berkeley: University of California Press, 2009.

COLOMBO, John Robert. Haunted Toronto. Toronto, Ontario: Hounslow Press, 1996.

DÉGH, Linda; VÁZSONYI, Andrew. The Memorate and the Proto-Memorate. The Journal of American Folklore, Vol. 87, No. 345 (Jul. - Sep., 1974), p. 225-239. Disponível em: http://www.jstor.org/stable/538735. Acesso em: 20/12/2015.

DICKERSON, Vanessa D. Victorian Ghosts in the Noontide: Women Writers and the Supernatural. Columbia, London: University of Missouri Press, 1996.

EISENBERG, Peter L. The Sugar Industry in Pernambuco: Modernization Without Change, 18401910. Berkeley, London: University of California Press, 1974.

FRANCO, Afonso Arinos de Melo. Contos: Pelo Sertão. São Paulo: Martins Fontes, 2006.

FREYRE, Gilberto. Assombrações do Recife Velho. Rio de Janeiro: Topbooks, 2000.

GORSE, Pierre-François. Ghost Stories (Histoires de Fantômes). In: BRUNEL, Pierre; VION-DURY, Juliette (Dirs.). Dictionnaire des mythes du fantastique. Limoges: Pulim, 2003, p. 149-158.

GREEN, Thomas A. (Ed.). Folklore: An Encyclopedia of Beliefs, Customs, Tales, Music, and Art. Volume 1. Santa Barbara, Oxford: ABC-CLIO, 1997.

GRIZ, Jayme. O Cara de Fogo. Recife: Museu do Açúcar, 1969.

GUREVITCH, Aaron. Historical Anthropology of the Middle Ages. Chicago: The University of Chicago Press, 1992.

HANDLEY, Sasha. Visions of an Unseen World: Ghost Beliefs and Ghost Stories in EighteenthCentury England. London: Pickering and Chatto, 2007.

HONKO, Lauri. Memorates and the Study of Folks Beliefs. Journal of the Folklore Institute, Indiana University Press, Vol. 1, No. 1/2, p. 5-19, 1964. Disponível em: http://www.jstor.org/stable/3814027. Acesso em: 20/12/2015.

LE GOFF, Jacques. Heróis e maravilhas da Idade Média. Petrópolis: Vozes, 2009.

História e Memória. Campinas: Editora da Unicamp, 1996.

Por amor às cidades. São Paulo: Editora da Unesp, 1998.

MOLINO, Jean. Le fantastique entre l'oral et l'écrit, Europe: Les fantastiques, $\mathrm{N}^{\circ}$ 611, p. 3-122, 1980.

ROLPH, Daniel N. "To Shoot, Burn, and Hang": Folk-history from a Kentucky Mountain Family and Community. Knoxville: The University of Tenesse Press, 1994.

REIS, Nestor Goulart. Os engenhos da Baixada Santista e do Litoral Norte de São Paulo. REVISTA USP, São Paulo, n.41, p. 62-73, março/maio 1999. 
SHARPE, Jim. A História vista de baixo, in: BURKE, Peter. A escrita da História. São Paulo: Editora Unesp, 1992, p. 47.

VANSINA, Jan M. Oral Tradition as History. London/Madison: The University of Wisconsin Press, 1985

\section{Recebido em 03/02/2016. Aprovado em 31/05/2016}

Title: From Mills to Mansions: memories and fictions in Gilberto Freyre and Jayme Griz Abstract: The aim of this paper is to analyze some ghost stories elaborated by the contemporaries Gilberto Freyre and Jayme Griz on format of accounts, compiled memories or interviews that concerning the supernatural. Jayme Griz collected oral accounts of ex slaves, descendant of slaves, workers of sugar's plantations and of workers of mechanized sugar production. Gilberto Freyre organized accounts of oral and documentary sources when worked as editor-in-chief of the old newspaper A Provincia, in 1929. He researches and transcribes stories of hauntings and haunted houses of cases that took place in the course of historical and particular files, and official police investigations on the city of Recife. Both describe, with different points of view, the memories of a world in transition between the $19^{\text {th }}$ and the $20^{\text {th }}$ centuries.

Keywords: Gilberto Freyre. Jayme Griz. History. Literature. Memory.

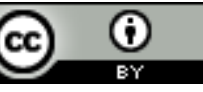

Este texto está licenciado com uma Licença Creative Commons Atribuição 4.0 Internacional. 